\title{
Humoral immunity responses against EGFR-positive tumor cells induced by xenogeneic EGFR expressed in the yeast Pichia pastoris
}

\author{
FANG FANG, PING CHEN, XIAN-CHENG CHEN, JIONG LI, YAN-JUN WEN and YU-QUAN WEI
}

State Key Laboratory of Biotherapy and Cancer Center, West China Hospital, West China Medical School, Sichuan University, Chengdu 610041, P.R. China

Received August 20, 2008; Accepted October 13, 2008

DOI: 10.3892/ijmm_00000115

\begin{abstract}
The breaking of immune tolerance against self epidermal growth factor receptor (EGFR) should be a promising approach for the treatment of those receptorpositive tumors. We have previously shown that human EGFR as a xenoantigen induced a specific antitumor activity against EGFR-positive mouse tumors. Our further studies demonstrated that a recombinant form of extracellular domain of mouse EGFR provoked active cellular immunity responses against EGFR-positive human tumors. In this study, we investigated whether the recombinant murine EGFR expressed in the yeast Pichia pastoris would induce humoral immunity responses against EGFR-positive human tumors. To test this concept, polyclonal immunoglobulin (IgG), which was produced by vaccinating the rabbits with the recombinant mEGFR, was purified from the sera of the rabbits. We evaluated the antitumor activity of the polyclonal $\mathrm{IgG}$ in the nude mice bearing A431 tumors. Mice were i.v. treated with the purified $\mathrm{IgG}$ at $100 \mathrm{mg} / \mathrm{kg} 1$ day before the mice were inoculated with the tumor cells and then twice per week for 4 weeks. Our results showed that the polyclonal IgG would efficiently inhibit the growth of the solid tumor in vivo. The antitumor effect of the polyclonal IgG may result from the increasing rate of apoptosis and induction of differentiation of the tumor cells in vivo. The present findings may provide insight into treatment of EGFRpositive tumors through induction of the humoral immunity responses based on xenogeneic homologous EGFR.
\end{abstract}

Correspondence to: Dr Yu-quan Wei, State Key Laboratory of Biotherapy and Cancer Center, West China Hospital, West China Medical School, Sichuan University, Chengdu 610041, P.R. China E-mail: yuquawei@hotmail.com

Key words: epidermal growth factor receptor, polyclonal antibodies, humoral immunity, immunotherapy

\section{Introduction}

EGFR belongs to the erbB receptor tyrosine kinase family consisting of four related transmembrane glycoprotein membrane receptors: EGFR/ErbB1/HER1, ErbB2/Neu/HER2, ErbB3/HER3 and ErbB4/HER4 (1). Increased expression of EGFR can markedly influence the growth properties of cells and leads to tumor development in nude mice in an EGFdependent manner $(2,3)$. In addition, autocrine and paracrine growth factor stimulation of the tumor is predominantly mediated by an EGFR-related pathway (4), which can result in growth advantage of tumor cells. Moreover, in many human tumors, EGFR is often overexpressed and/or mutated with its constitutive activation leading to proliferation, reduced apoptosis, increased angiogenesis, increased motility, invasion and metastasis (5).

The overexpression and aberrant function of EGFR and its ligands and co-receptors in a wide spectrum of epithelial cancers make it an ideal target for strategies to treat human tumors (1). Accordingly, monoclonal antibodies (mAb) which are targeted the extracellular ligand-binding, domain or the intracellular tyrosine kinase signaling cascade of EGFR have shown efficacy as antitumor agents. Administration of antibodies, such as cetuximab, ABX-EGF and mAb 806 is capable of inhibiting tumor growth through both certain direct and indirect mechanisms (6-8).

The breaking of immune tolerance against self EGER and induction of autoimmunity against receptor-positive tumors should be another useful approach for the treatment of EGFRpositive tumor cells with active immunization. We have previously shown human EGFR as a xenoantigen inducing specific immune responses in mouse and cross-reacting with mouse EGFR and it resulted in therapeutic benefits for EGFR-positive mouse tumors (9). Our further studies showed that a recombinant form of extracellular domain of mouse EGFR, in the presence of DCs, could activate human peripheral $\mathrm{T}$ cells to proliferate. Therefore, the induced responses could cross-react with human EGFR and kill EGFR-positive human cancer cells (10). However, whether the xenogeneic EGFR vaccine could induce humoral immunity responses against the EGFR-positive human tumors is not clear. 
In this study, we firstly developed a methanol-trophic yeast expression system, Pichia pastoris (11-13), which can express the secreted forms of murine EGFR ectodomain. Then the rabbits were subcutaneously vaccinated with the recombinant protein once a week for four weeks. The EGFR-positive human epidermoid carcinoma A431 was treated with the purified immune IgG in vitro and in vivo. Our data showed that the polyclonal $\mathrm{IgG}$ would efficiently inhibit the growth of tumor and increase the apoptotic rate of EGFR-positive human tumor cells. Interestingly, this therapy induced differentiation of the tumor cells in vivo.

\section{Materials and methods}

Preparation of recombinant EGFR. The nucleotide sequence encoding the extracellular domain of murine EGFR was PCR amplified from pcDNA3.1-mEGFR (9) and cloned into an expression vector $\mathrm{pPICZ} \alpha \mathrm{A}$ (Invitrogen). The recombinant plasmid was linearized by the restriction enzyme $\mathrm{SacI}$ and was transformed into $P$. pastoris GS115. The expression of the recombinant protein was performed, as previously described (11-13). Briefly, a screened colony of yeast cells was selected and inoculated into $50 \mathrm{ml} \mathrm{BMGY}$, shaken at $250 \mathrm{rpm}$ for 1 day at $30^{\circ} \mathrm{C}$, the cells were pelleted and resuspended in $350 \mathrm{ml}$ BMMY. Following further 2 days of induction at $30^{\circ} \mathrm{C}$, the recombinant $\mathrm{mEGFR}$ protein was secreted into the culture supernatant as a soluble form. The supernatant was harvested by centrifugation and analyzed by SDS-PAGE and Western blot analysis.

Purified mEGFR was prepared using a nickel-chelating column (Chelating Sepharose Fast Flow, Amersham Pharmacia Biotech, Uppsala, Sweden) on the chromatography system (AKTA, Amersham Pharmacia Biotech). The protein was eluted from the column with a linear gradient of imidazole, which was then dialyzed against the buffer containing decreased imidazole concentration (14). Finally, it was dialyzed by phosphate-buffered saline (PBS). Purified proteins were confirmed by SDS-PAGE and Western blot analysis (9).

Rabbit immunizations and isolation of immunoglobulin. Purified mEGFR were dissolved in PBS before vaccinating and were mixed with an equal volume of aluminum hydroxide (ALUM) adjuvant at $1 \mathrm{mg} / \mathrm{ml}$ for 30 to $60 \mathrm{~min}$ as described (11-13). The rabbits were subcutaneously immunized with mEGFR (0.5 mg per rabbit) once a week for four weeks in a volume of $0.2 \mathrm{ml}$, or appropriate control injections in a volume of $0.2 \mathrm{ml}$ of PBS solution and ALUM adjuvant at the same time point. Serum from the rabbits, 2 weeks after the last treatment, was used for isolation of immune $\mathrm{IgG}$. Preimmune $\operatorname{IgG}$ was prepared from rabbits prior to the first inoculation of mEGFR. Blood was allowed to clot overnight at $4^{\circ} \mathrm{C}$ and serum was removed from the top of the mixture after centrifugation at $10,000 \mathrm{x}$ g. Immunoglobulin was isolated using Econo-Pac serum IgG purification kit (Bio-Rad). Purified IgG $(\sim 20 \mathrm{mg} / \mathrm{ml})$ (free of complement and other components) was obtained from $50 \mathrm{cc}$ of rabbit blood per bleed as described (15).

ELISA/Western blotting. For ELISA, tumor cells $\left(5 \times 10^{3}\right)$ were grown overnight in the wells of 96-well plates. The cells were fixed in $4 \%$ formalin for $5 \mathrm{~min}$. Plates were washed with PBST (0.05\% Tween-20 in PBS) and were blocked for $1 \mathrm{~h}$ at $37^{\circ} \mathrm{C}$ with $200 \mu \mathrm{l} /$ well blocking buffer ( $1 \%$ bovine serum albumin in PBST). The first antibody was diluted from 1:2000 to $1: 20,000$ in PBST was added for $2 \mathrm{~h}$ at $37^{\circ} \mathrm{C}$, followed by incubating with the second antibody (goat anti-rabbit conjugated to alkaline phosphatase, 1:10,000, Santa Cruz) for $30 \mathrm{~min}$. Subsequently, alkaline phosphatase substrate BCIP/NCP (Sigma) was added to the wells. Enzyme activity was measured with an enzyme-linked immunosorbent assay (ELISA) reader (Bio-Rad Laboratories, Hercules, CA) (16).

Western blot analysis was performed as described (16). Briefly, purified mEGFR was separated by SDS-PAGE. Then gels were electroblotted with Sartoblot onto a polyvinylidene difluoride (PVDF) membrane. Membrane blots were blocked at $4{ }^{\circ} \mathrm{C}$ in $5 \%$ nonfat dry milk, washed and probed with rabbit sera at 1:3000. Blots were then washed and incubated with a alkaline phosphatase conjugated secondary antibody. The immunoreactive proteins were identified by using BCIP/NCP as the developing agent.

Cell line, media, growth conditions. Human epidermoid carcinoma A431 cells was obtained from the American Type Culture Collection (ATCC) and grew in DMEM supplement with $10 \%$ FBS. These tumor cell cultures were maintained in a $37^{\circ} \mathrm{C}$ incubator with a humidified $5 \% \mathrm{CO}_{2}$ atmosphere.

Cell viability/MTT assays. The mEGFR antibody-mediated inhibition of tumor cell proliferation was carried out by MTT assays $(15,17)$. Briefly, exponentially growing tumor cells $\left(5 \times 10^{3}\right.$ cells/well in 96 -well plates) were incubated with varying concentrations of antibody (approximately no more than $1 \mathrm{mg} / \mathrm{ml}$ of protein) and then subjected to MTT assay. The antibody remained in the media for the full duration of the assay. Using daily time points, MTT reagent was added to the wells $(5 \mathrm{mg} / \mathrm{ml})$ and incubated at $37^{\circ} \mathrm{C}$ for $4 \mathrm{~h}$. Subsequently, the cells were solubilized with IPA/4N HCl. The samples were then read at wavelength of $570 \mathrm{~nm}$.

Tumor growth inhibition study. All studies involving mice were approved by the Institute's Animal Care and Use Committee. Female athymic BALB/c nude mice, 6-8 weeks old, were maintained in pathogen-free conditions and fed sterile chow. A431 cells $\left(1 \times 10^{6}\right)$ in $0.1 \mathrm{ml}$ of PBS were injected s.c. into the right flank of each mouse. The animals were randomly assigned into one of the following three groups $(\mathrm{n}=5)$ and treated with PBS, pre-immune IgG or immune IgG. Mice were i.v. treated with the purified $\mathrm{IgG}$ at $100 \mathrm{mg} / \mathrm{kg} 1$ day before the mice were inoculated with the tumor cells and then twice per week for 4 weeks. Additional control animals were i.v. injected with same volume of PBS as described above. Tumor volume and survival time were observed. Tumor size was determined by caliper measurement of the largest and perpendicular diameters every 3 days. Tumor volume was calculated according to the formula $\mathrm{V}=0.52 \mathrm{ab}^{2}$, where $\mathrm{a}$ is the largest superficial diameter and $\mathrm{b}$ is the smallest superficial diameter. The mice were sacrificed by cervical dislocation when they became moribund. Excised tumors were weighed before their fixation in $10 \%$ formalin $(14,16)$. 
A

B

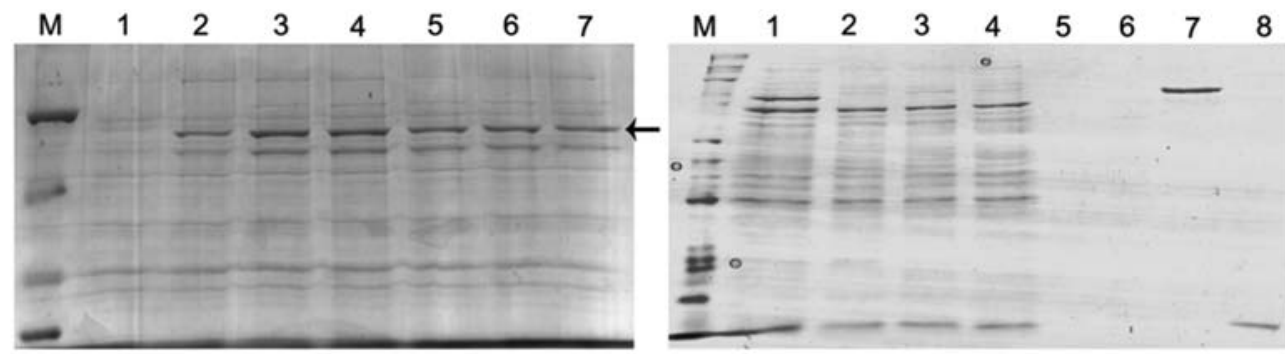

C

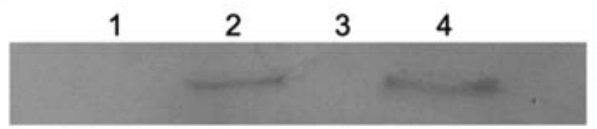

Figure 1. Expression, purification and identification of the recombinant protein. (A) The expression of the recombinant mEGFR protein in the culture supernatant was analyzed by SDS-PAGE. M, Protein molecular weight markers (Fermentas \#SM0431); lane 1, supernatant before induction; lanes 2-7, supernatants (12, 24, $36,48,60$ and $72 \mathrm{~h}$ ) after induction (arrow, the recombinant mEGFR protein). (B) Recombinant mEGFR was purified using a nickel-chelating column and assayed by SDS-PAGE. M, Protein molecular weight markers (Fermentas\#SM0431); lane 1, induced expression supernatant; lanes 2-8, the products eluted by linear gradient of imidazole; lane 7, the purified recombinant mEGFR. (C) Western blot analysis confirmed the expressed supernatant and purified mEGFR (monoclonal anti-EGFR clone 29.1; Sigma E 2760). Lane 1, supernatant before induction; lane 2, supernatant after induction; lane 3 , the products eluted by any concentration of imidazole except $50 \mathrm{mmol}$ and lane 4 , the purified $\mathrm{mEGFR}$.

Histological analysis. Sections of paraffin-embedded from each group were stained with hematoxylin and eosin (H\&E), according to the standard procedures (14). H\&E section along the largest diameter of the tumor was scanned in the low field using the computer aided image analysis system Quantimet 600 and Qwin software (Leica, Benshaim, Germany). The total tumor area and necrotic tumor area were subsequently marked by the examiners on the screen. The percentage of the tumor necrosis area to total tumor area was evaluated by the image analysis system.

Quantitative assessment of apoptosis. Tumor sections were prepared, as described previously (14). Terminal deoxynucleotidyl transferase-mediated nick end-labeling (TUNEL) staining was done using an in situ cell death detection kit (DeadEnd $^{\text {TM }}$ Fluorometric TUNEL System, Promega, Madison, USA) following the manufacturer's protocol. It is based on the enzymatic addition of digoxigenin-nucleotide to the nicked DNA by the recombinant terminal deoxynucleotidyl transferase (rTdT) (18). In tissue sections, four equal-sized fields were randomly chosen and analyzed. Density was evaluated in each field, yielding the density of apoptotic cells (apoptosis index).

Statistical analysis. Data were assayed by ANOVA and Student's t-test. For the survival time of animals, Kaplan-Meier curves were established for each group and the survivals were compared by means of the log-rank test. Differences between means or ranks as appropriate were considered significant at $\mathrm{P}<0.05$

\section{Results}

Expression and purification of $m E G F R$. Murine EGFR was expressed in $P$. pastoris GS115 secretively and SDS-PAGE analysis revealed that the recombinant protein with 6-His tag at the N-terminal was $\sim 95 \mathrm{kDa}$ (Fig. 1A). Then, Nickel

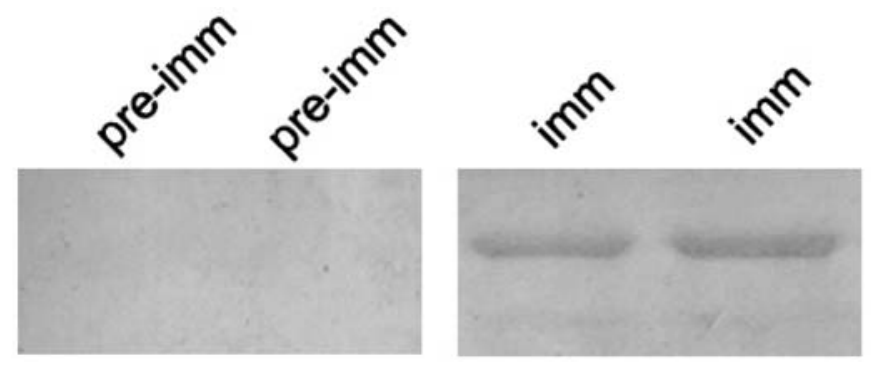

Figure 2. Western blot analysis of polyclonal antibodies. Recombinant mEGFR can be recognized by the sera isolated from rabbits immunized with mEGFR, but negative staining from the pre-immune sera in Western blot analysis.

chelataffinity chromatography was employed to purify large quantities of mEGFR (14) and the recombinant protein was eluted from the column with $50 \mathrm{mmol}$ imidazole. The presence of recombinant mEGFR in the eluted fractions was confirmed by SDS-PAGE (Fig. 1B) and Western blot analysis using an anti-mEGFR antibody (Fig. 1C).

Characterizations of the polyclonal antibodies. To investigate the possibility that vaccination of rabbits with mEGFR could generate a cross-reacting response with human EGFR, the rabbits were inoculated with the purified recombinant mEGFR. Sera from mEGFR-immunized rabbits were assayed for the presence of mEGFR-specific autoantibodies in Western blot analysis. Only sera from rabbits immunized with mEGFR recognized the recombinant protein in Western blot analysis (Fig. 2). In contrast, the sera isolated from the pre-immunized sera showed negative staining (Fig. 2). Pre-immune and immune IgG were tested for their ability to bind EGFRpositive or -negative tumor cells of both mouse and human origins (Fig. 3). There was a 4-9- and 3-8-fold difference in the binding of LL/2c and A431 (EGFR-positive) cells by immune antibody compared with pre-immune. The binding 
A

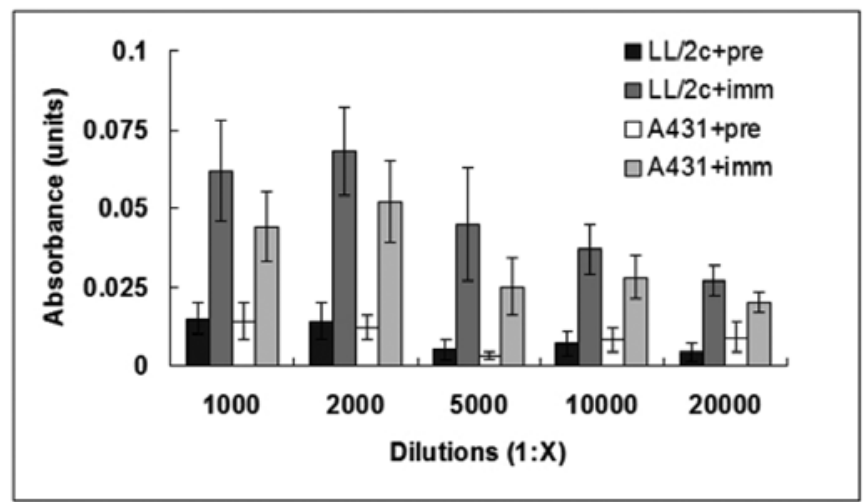

B

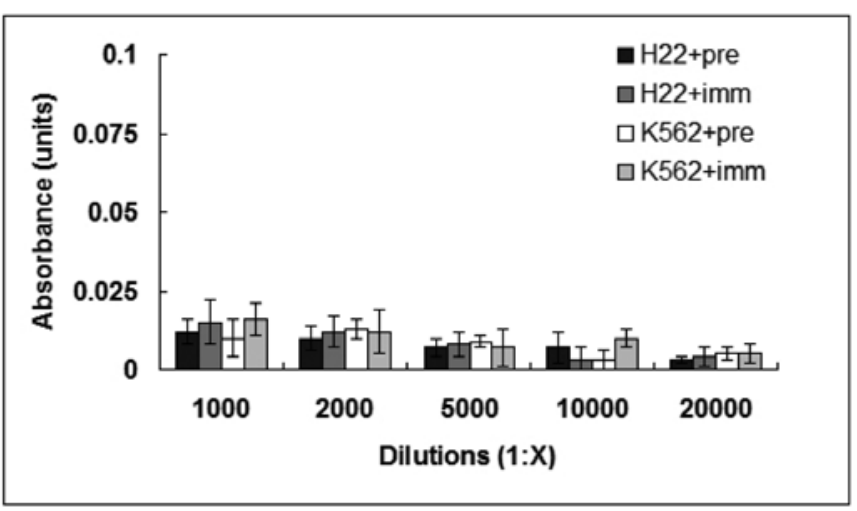

Figure 3. ELISA of rabbit immunoglobulin on EGFR-positive (A) and -negative (B) tumor cell types. Pre-immune and immune rabbit IgG was incubated with various tumor cells at dilutions 1:1000 to 1:20,000. After the addition of alkaline phosphatase conjugated secondary antibody, absorbance was measured at 615 nm. Columns, mean value of 6 wells for every dilution and bars, \pm SD.

A

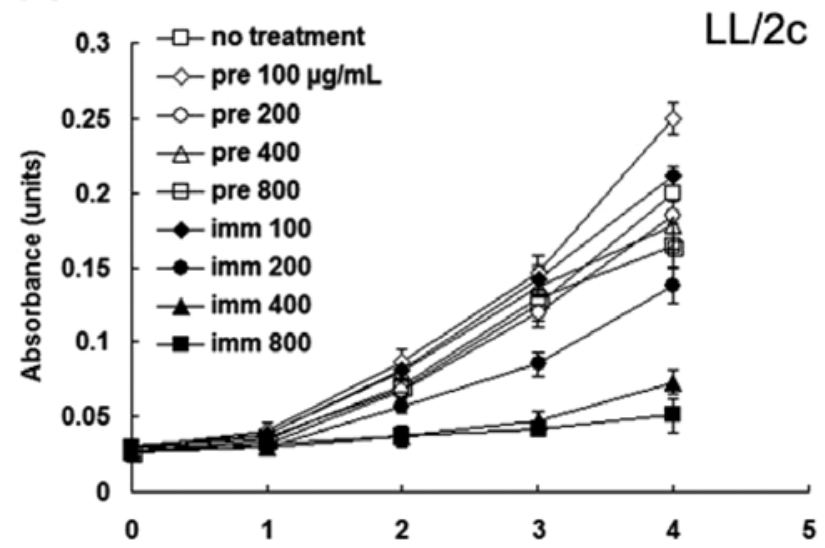

C

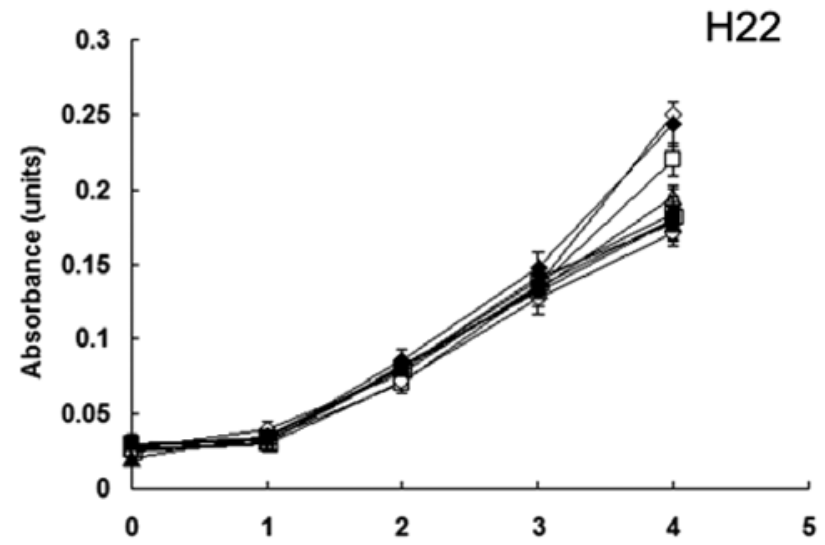

B

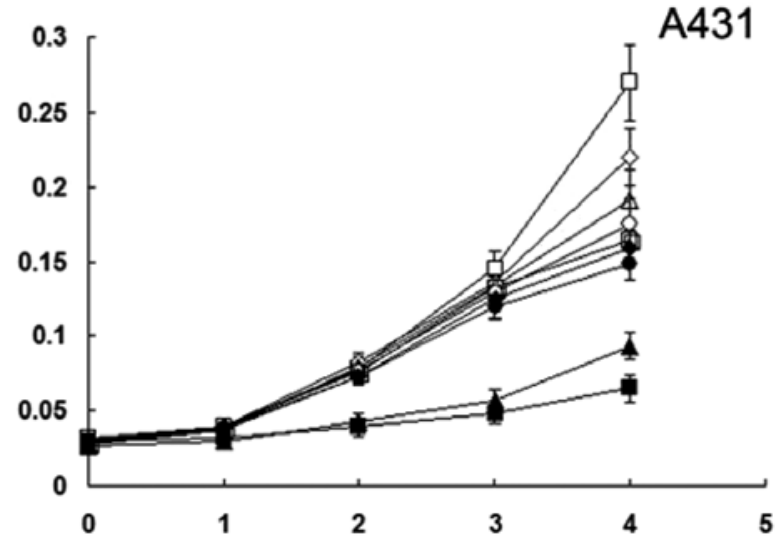

D

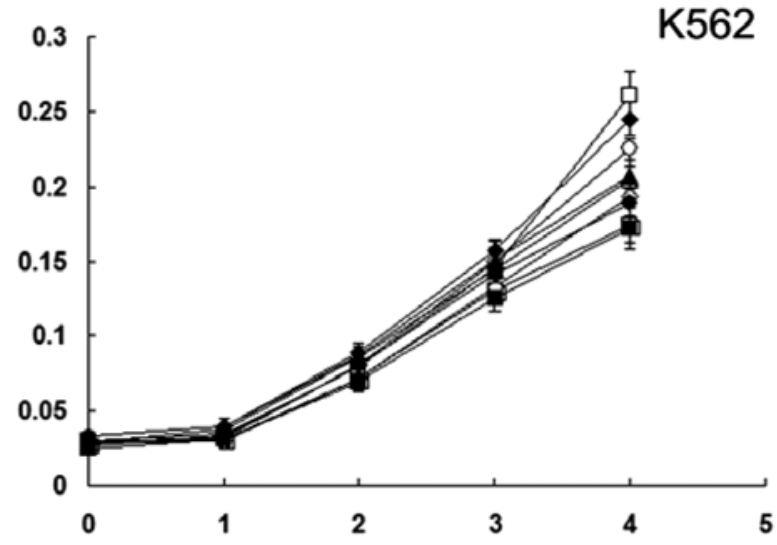

Days in culture

Figure 4. Inhibition of tumor cell proliferation by rabbit immune IgG. Dose response effects of pre-immune vs. immune IgG treatment of EGFR-positive (A and B) and -negative (C and D) tumor cells as determined by cell growth. Treatment was initiated on Day 0 and MTT assays were performed daily for 4 days. Points are the average of three wells \pm SD.

was dose-dependent, dilutions of 1:1000 and 1:2000 showing greater binding to the EGFR-positive tumor cells compared with 1:5000 or 1:10,000 (Fig. 3A). However, no significant difference was observed in the binding of EGFR-negative tumor cells by immune IgG compared with the pre-immune (Fig. 3B). 
A

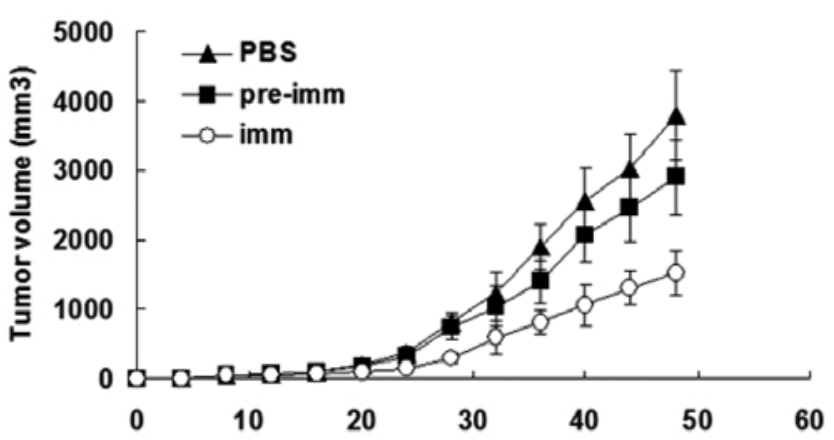

B

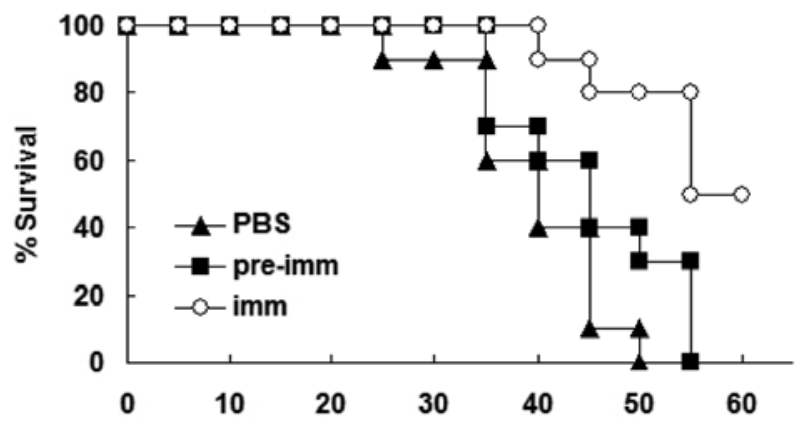

\section{Days after tumor cells injection}

Figure 5. Tumor suppression and survival advantage in mice. Mice were i.v. injected with immune IgG, or pre-immune IgG, or same volume of PBS. Disease progression and outcome were determined as described in Materials and methods. (A) Suppression of s.c. tumor growth in mice. The graph shows treatment with immune $\mathrm{IgG}$ resulting in significant tumor growth inhibition vs. $\mathrm{PBS}(\mathrm{P}<0.05)$ or pre-immune $\mathrm{IgG}(\mathrm{P}<0.05)$ groups from day 28 after tumor cell inoculation. Points, average tumor volume; bars, \pm SD. (B) A significant increase in survival in the immune IgG-treated mice compared with the control groups $(\mathrm{P}<0.01$, by log-rank test $)$.
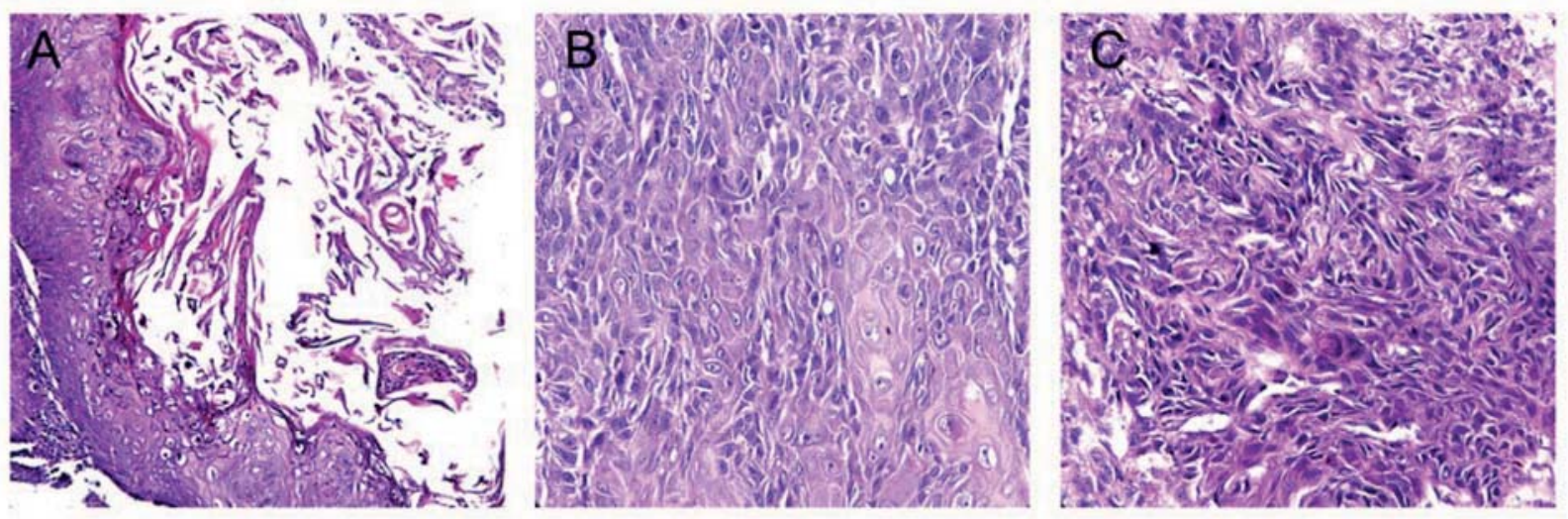

Figure 6. Histological analysis of tumors. Tumor species were prepared as described in Materials and methods. Sections of paraffin-embedded from each group were stained with H\&E. Tumor tissues from PBS (C) or pre-immune IgG (B) treated groups had large areas of confluent tumor cells with little or no tumor tissue necrosis. Whereas, tumor tissues from the immune IgG-treated group has almost none of these typical pathological signs and considerable epithelial cyst spread in the tumor tissues (A).

Rabbit immune IgG inhibits EGFR-positive tumor cell proliferation in vitro but not the EGFR-negative tumor cells. The inhibition of tumor cell proliferation by rabbit immune IgG was determined by MTT assays. There was a dose response effect observed on the EGFR-positive murine (LL/2c) and human (A431) tumor cells for the immune IgG with $400 \mu \mathrm{g} / \mathrm{ml}$ and higher showing inhibition (Fig. 4A and B). No effect was observed on the EGFR-negative (H22 and K562) tumor cells (Fig. 4C and D).

Tumor growth inhibition. Tumor volume and life span of mouse assay showed that the rabbit immune $\operatorname{IgG}$ resulted in effective suppression of tumor growth. Treatment with the immune $\operatorname{IgG}$ resulting in an 8 day delay of tumor growth to reach a volume of $800 \mathrm{~mm}^{3}$ compared with PBS control (Fig. 5A). Therapy with the immune $\mathrm{IgG}$ resulted in a significant increase in life span $(\mathrm{P}<0.01$, by log-rank test; Fig. 5B). Immune IgG treatment resulted in apparent tumor inhibition vs. PBS controls $(\mathrm{P}<0.01)$ or pre-immune $\mathrm{IgG}$. Tumor growth inhibition was calculated using the mean excised tumor weight after completion of treatment for each group.

Histological analysis. Histologically, those immune IgGtreated tumors showed visible responses with homogeneous necrosis that was distinguishable in size and morphology from those of the control groups. Tumor tissues from the control mice had large areas of cancer nest, horny pearl and intercellular bridge, which are typical pathological signs associated with epithelial human squamous carcinoma (Fig. 6B and C). Wherease, tumor tissues from mEGFR group had almost none of these typical pathological signs and considerable epithelial cyst spread in the tumor tissues (Fig. 6A).

Therapeutic effect on apoptosis. To explore the role of immune IgG on apoptosis of tumor cells, tumor sections were 

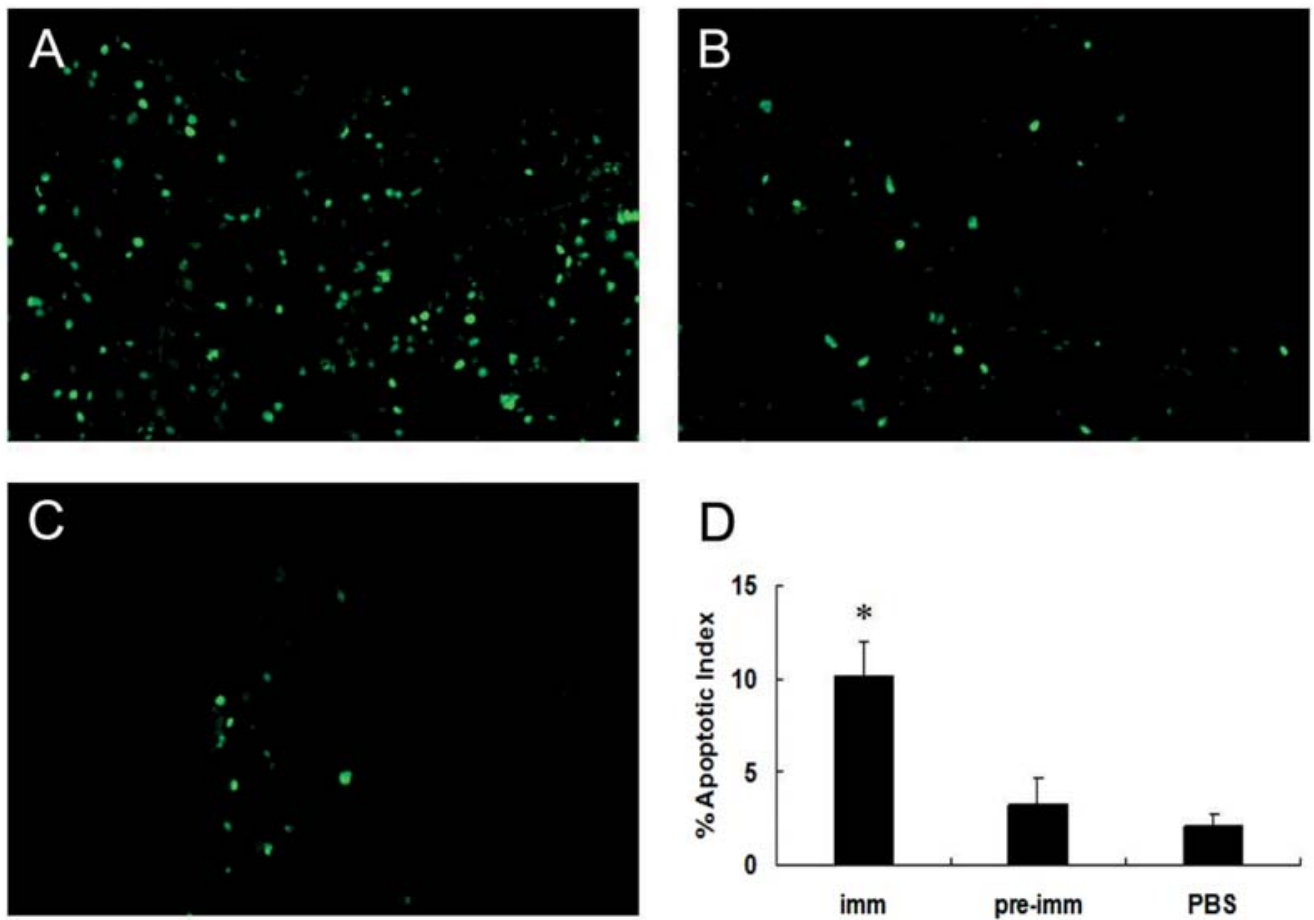

Figure 7. Assays for the detection of apoptosis. Apoptotic tumor cells within tumor tissues were elevated by TUNEL assays, as described in Materials and methods. Representative sections from tumor tissues are presented: immune $\operatorname{IgG}(\mathrm{A})$, pre-immune $\operatorname{IgG}(\mathrm{B})$ and PBS (C). The bar represents apoptotic index within tissues (D). The treatment with immune $\operatorname{IgG}$ showed an apparent increment of apoptotic cells within the tumor tissues vs. the controls $(\mathrm{P}<0.01)$. Columns, mean apoptotic index of cancer cells and bars, \pm SD. ${ }^{*} \mathrm{P}<0.05$ compared with pre-immune IgG or PBS group.

subjected to terminal deoxynucleotidyl transferase-mediated nick end-labeling assays for the respective determination of apoptotic index. Immune IgG therapy resulted in a significant increase of apoptotic cancer cells (Fig. 7). Data are shown as the mean apoptotic index \pm standard deviations of cancer cells as percent normalized to apoptotic index of cancer cells (Fig. 7).

\section{Discussion}

EGFR is a well-characterized tumor-associated antigen overexpressed in many human tumors, including non-small cell lung cancer (NSCLC) $(19,20)$, cancer of the breast (21), the bladder (22) and the brain (23) and has served as a target for various antitumor therapies $(1,5-10,24)$. The success of some anti-EGFR monoclonal antibodies, including C225 (also known as cetuximab), ABX-EGF and mAb 806 (6-8), suggested that therapeutic cancer vaccines inducing antiEGFR antibodies could also work (25). However, the immunity to self EGFR is presumably difficult to elicit by vaccines based on self or syngeneic EGFR due to the immune tolerance acquired during the development of immune system (9). Our group has previously reported immunization of mice with the plasmid DNA encoding human EGFR as vaccine by the breaking of the immune tolerance against EGFR in a cross-reaction between the xenogeneic homologous and self EGFR (9). Our further studies were designed to investigate the possible of application of this strategy for the treatment of human tumors and found that the recombinant truncated mouse EGFR could induce human $\mathrm{T}$ lymphocyte responses against EGFRpositive human tumor cells (10).
The present study was designed to test whether the mEGFR vaccine could induce a humoral immunity against the EGFR-positive human tumor cells. Our results showed that the purified IgG from the rabbits immunized with recombinant mEGFR cross-reacted with the xenogeneic homologous EGFR (Fig. 3) and inhibit the proliferation of the EGFRpositive murine and human tumor cells (Fig. 4). In vivo studies demonstrated that the IgG reduced the growth of tumor and improved the survival time of tumor-bearing mice (Fig. 5).

The mechanism of the antineoplastic effect of the polyclonal IgG may be related to an inhibitory or apoptotic effect on the EGFR-positive tumor cells. We observed that the immune IgG inhibited the proliferation of EGFR-positive tumor cells in vitro, while the EGFR-negative ones did not. Though the antineoplastic activity seen in vivo appears to be broad, the antitumor efficacy of the immune IgG may in part result from the increased induction of apoptosis. This suggestion is supported by the present finding. More apparent apoptotic cells in the tumors treated with the immune IgG was found compared with the pre-immune or PBS groups (Fig. 7). Previously, evidence indicated that EGFR blockade leads to the observed increase in tumor cell apoptosis (26-28). Our findings, that the inducing of apoptosis within tumor cells is through the blocking of EGFR, coincide with previous studies (26-28).

Furthermore, our findings have shown that during treatment with the immune $\operatorname{IgG}$, the tumor cells were undergoing terminal differentiation. In agreement with our findings, Modjtahedi et al have shown that antibodies which block the binding of EGF and transforming growth factor $\alpha$ to the EGFR inhibited the growth of EGFR-overexpressing tumors 
by directing terminal differentiation $(26,29,30)$. These studies also provided evidence for a relationship between the in vivo antitumor activity of xenogeneic homologous induced $\mathrm{IgG}$ and their capacity to induce differentiation of cancer cells.

EGFR is one of the multifunctional transmembrane proteins with intrinsic tyrosine kinase activity and post-translational modifications inducing structural changes are important to the functions of the protein (31-33). Recently, Li et al suggested that the antibodies against the extracellular region of EGFR are structure based (34). Thus, the properly modified and folded recombinant EGFR may be important to induce antibodies against the EGFR-positive tumor. In this study, we utilized the methylotrophic yeast Pichia pastoris (11-13), one of the widely used eukaryotic organisms for expression of recombinant proteins, to express the mEGFR. The Pichia expression system is known to possess post-translational mechanisms which produce recombinant proteins with biological functions that are almost similar to the native proteins (35). Our results showed that the $\operatorname{IgG}$ from the rabbits immunized with the recombinant mEGFR was successfully cross-reacted with the xenogeneic homologous EGFR and efficiently inhibited the growth of the A431 xenograft tumors.

In summary, the present study showed that the purified IgG from the rabbits immunized with recombinant mEGFR expressed in Pichia pastoris, which may increase the antigenicity and immunogenicity of the antigen, crossreacted with xenogeneic homologues and inhibit the growth of human EGFR-positive tumors in vitro and in vivo. The present findings provide further evidence of the anti-tumor effects of xenogeneic EGFR and may be of importance for the further exploration of the application of this vaccine in the protection and treatment of human cancer.

\section{Acknowledgements}

This study was financially supported by Chinese Key Basic Research Program (2004CB518807), the projects of National Natural Science Foundation of China and National 973 Program.

\section{References}

1. Arteaga CL: ErbB-targeted therapeutic approaches in human cancer. Exp Cell Res 284: 122-130, 2003.

2. Velu TJ, Beguinot L, Vass WC, Willingham MC, Merlino GT, Pastan I and Lowy DR: Epidermal-growth-factor-dependent transformation by a human EGF receptor proto-oncogene. Science 238: 1408-1410, 1987.

3. Di Fiore PP, Pierce JH, Fleming TP, Hazan R, Ullrich A, King CR, Schlessinger J and Aaronson SA: Overexpression of the human EGF receptor confers an EGF-dependent transformed phenotype to NIH 3T3 cells. Cell 51: 1063-1070, 1987.

4. Gleave ME, Hsieh JT, Wu HC, Hong SJ, Zhau HE, Guthrie PD and Chung LW: Epidermal growth factor receptor-mediated autocrine and paracrine stimulation of human transitional cell carcinoma. Cancer Res 53: 5300-5307, 1993.

5. Mendelsohn J: The epidermal growth factor receptor as a target for cancer therapy. Endocr Relat Cancer 8: 3-9, 2001

6. Mendelsohn $\mathrm{J}$ and Baselga J: The EGF receptor family as targets for cancer therapy. Oncogene 19: 6550-6565, 2000.

7. Grunwald V and Hidalgo M: Developing inhibitors of the epidermal growth factor receptor for cancer treatment. J Natl Cancer Inst 95: 851-867, 2003.
8. Mishima K, Johns TG, Luwor RB, Scott AM, Stockert E, Jungbluth AA, Ji XD, Suvarna P, Voland JR, Old LJ, Huang HJ and Cavenee WK: Growth suppression of intracranial xenografted glioblastomas overexpressing mutant epidermal growth factor receptors by systemic administration of monoclonal antibody (mAb) 806, a novel monoclonal antibody directed to the receptor. Cancer Res 61: 5349-5354, 2001.

9. Lu Y, Wei YQ, Tian L, Zhao X, Yang L, Hu B, Kan B, Wen YJ, Liu F, Deng HX, Li J, Mao YQ, Lei S, Huang MJ, Peng F, Jiang Y, Zhou H, Zhou LQ and Luo F: Immunogene therapy of tumors with vaccine based on xenogeneic epidermal growth factor receptor. J Immunol 170: 3162-3170, 2003.

10. Hu B, Wei YQ, Tian L, Zhao X, Lu Y, Wu Y, Yao B and Zhang XW: Human $\mathrm{T}$ lymphocyte responses against lung cancer induced by recombinant truncated mouse EGFR. Cancer Immunol Immunother 55: 386-393, 2006.

11. Byrne LJ, O'Callaghan KJ and Tuite MF: Heterologous gene expression in yeast. Methods Mol Biol 308: 51-64, 2005.

12. Hamilton SR, Bobrowicz P, Bobrowicz B, Davidson RC, Li H, Mitchell T, Nett JH, Rausch S, Stadheim TA, Wischnewski H, Wildt $\mathrm{S}$ and Gerngross TU: Production of complex human glycoproteins in yeast. Science 301: 1244-1246, 2003.

13. Ogawa M, Nakamura S, Atsuchi T, Tamiya T, Tsuchiya T and Nakai S: Macromolecular antimicrobial glycoprotein, achacin, expressed in a methylotrophic yeast Pichia pastoris. FEBS Lett 448: 41-44, 1999.

14. Li G, Tian L, Hou JM, Ding ZY, He QM, Feng P, Wen YJ, Xiao F, Yao B, Zhang R, Peng F, Jiang Y, Luo F, Zhao X, Zhang L, Zhou Q and Wei YQ: Improved therapeutic effectiveness by combining recombinant $\mathrm{CXC}$ chemokine ligand 10 with Cisplatin in solid tumors. Clin Cancer Res 11: 4217-4224, 2005.

15. Scappaticci FA, Contreras A, Boswell CA, Lewis JS and Nolan G: Polyclonal antibodies to xenogeneic endothelial cells induce apoptosis and block support of tumor growth in mice. Vaccine 21: 2667-2677, 2003.

16. Liu JY, Wei YQ, Yang L, Zhao X, Tian L, Hou JM, Niu T, Liu F, Jiang Y, Hu B, Wu Y, Su JM, Lou YY, He QM, Wen YJ, Yang JL, Kan B, Mao YQ, Luo F and Peng F: Immunotherapy of tumors with vaccine based on quail homologous vascular endothelial growth factor receptor-2. Blood 102: 1815-1823, 2003.

17. Carmichael J, DeGraff WG, Gazdar AF, Minna JD and Mitchell JB: Evaluation of a tetrazolium-based semiautomated colorimetric assay: assessment of chemosensitivity testing. Cancer Res 47: 936-942, 1987.

18. Ben-Sasson SA, Sherman Y and Gavrieli Y: Identification of dying cells - in situ staining. Methods Cell Biol 46: 29-39, 1995.

19. Berger MS, Gullick WJ, Greenfield C, Evans S, Addis BJ and Waterfield MD: Epidermal growth factor receptors in lung tumours. J Pathol 152: 297-307, 1987.

20. Veale D, Kerr N, Gibson GJ and Harris AL: Characterization of epidermal growth factor receptor in primary human non-small cell lung cancer. Cancer Res 49: 1313-1317, 1989.

21. Sainsbury JR, Farndon JR, Sherbet GV and Harris AL: Epidermal-growth-factor receptors and oestrogen receptors in human breast cancer. Lancet 1: 364-366, 1985.

22. Neal DE, Marsh C, Bennett MK, Abel PD, Hall RR, Sainsbury JR and Harris AL: Epidermal-growth-factor receptors in human bladder cancer: comparison of invasive and superficial tumours. Lancet 1: 366-368, 1985.

23. Wong AJ, Bigner SH, Bigner DD, Kinzler KW, Hamilton SR and Vogelstein B: Increased expression of the epidermal growth factor receptor gene in malignant gliomas is invariably associated with gene amplification. Proc Natl Acad Sci USA 84: 6899-6903, 1987.

24. Ciardiello F and Tortora G: EGFR antagonists in cancer treatment. N Engl J Med 358: 1160-1174, 2008.

25. Ramírez BS, Alpízar YA, Fernández DR, Hidalgo GG, Capote AR, Rodríguez RP and Fernández LE: Anti-EGFR activation, anti-proliferative and pro-apoptotic effects of polyclonal antibodies induced by EGFR-based cancer vaccine. Vaccine 26: 4918-4926, 2008.

26. Modjtahedi H, Affleck K, Stubberfield C and Dean C: EGFR blockade by tyrosine kinase inhibitor or monoclonal antibody inhibits growth, directs terminal differentiation and induces apoptosis in the human squamous cell carcinoma HN5. Int J Oncol 13: 335-342, 1998. 
27. Kari C, Chan TO, Rocha de Quadros M and Rodeck U: Targeting the epidermal growth factor receptor in cancer: apoptosis takes center stage. Cancer Res 63: 1-5, 2003.

28. Reusch U, Sundaram M, Davol PA, Olson SD, Davis JB Demel K, Nissim J, Rathore R, Liu PY and Lum LG: Anti-CD3 $\mathrm{X}$ anti-epidermal growth factor receptor (EGFR) bispecific antibody redirects T-cell cytolytic activity to EGFR-positive cancers in vitro and in an animal model. Clin Cancer Res 12: 183-190, 2006.

29. Modjtahedi H, Eccles S, Sandle J, Box G, Titley J and Dean C: Differentiation or immune destruction: two pathways for therapy of squamous cell carcinomas with antibodies to the epidermal growth factor receptor. Cancer Res 54: 1695-1701, 1994.

30. Modjtahedi H, Moscatello DK, Box G, Green M, Shotton C Lamb DJ, Reynolds LJ, Wong AJ, Dean C, Thomas H and Eccles S: Targeting of cells expressing wild-type EGFR and type-III mutant EGFR (EGFRvIII) by anti-EGFR MAb ICR62: a two-pronged attack for tumour therapy. Int J Cancer 105: 273-280, 2003
31. Downward J, Parker P and Waterfield MD: Autophosphorylation sites on the epidermal growth factor receptor. Nature 311: 483-485, 1984.

32. Downward J, Waterfield MD and Parker PJ: Autophosphorylation and protein kinase $\mathrm{C}$ phosphorylation of the epidermal growth factor receptor. Effect on tyrosine kinase activity and ligand binding affinity. J Biol Chem 260: 14538-14546, 1985.

33. Kaleem A, Ahmad I, Hoessli DC, Walker-Nasir E, Saleem M, Shakoori AR and Nasir-Ud-Din: Epidermal growth factor receptors: function modulation by phosphorylation and glycosylation interplay. Mol Biol Rep 2008 Mar 14 (Epub ahead of print).

34. Li S, Kussie P and Ferguson KM: Structural basis for EGF receptor inhibition by the therapeutic antibody IMC-11F8. Structure 16: 216-227, 2008

35. Lau YL and Fong MY: Toxoplasma gondii: serological characterization and immunogenicity of recombinant surface antigen 2 (SAG2) expressed in the yeast Pichia pastoris. Exp Parasitol 119: 373-378, 2008. 